\title{
A pós-graduação brasileira: sua construção assimétrica e algumas tentativas de superação
}

Elias Nazareno. Universidade Federal de Goiás

Alexandre Ferraz Herbetta. Universidade Federal de Goiás

\section{Resumo}

O texto a seguir trata da origem e desenvolvimento do sistema de pós-graduação no Brasil, desde sua implementação na década de 1960 até os dias de hoje. Para isso, realiza-se uma análise especialmente dos seis Planos Nacionais de Pós-Graduação. Percebe-se que a despeito de um incremento regular no número de programas e na produção científica, ao longo do referido período analisado, reproduz-se igualmente as assimetrias e desigualdades regionais e espaciais. Tais assimetrias geram impactos interessantes para se pensar no futuro da produção científica no país, sobretudo aqueles ligados à lógica que privilegia programas de pós-graduação localizados nas regiões sul, sudeste e o Distrito Federal.

Palavras-chave: pós-graduação; assimetrias; ciência; desigualdade.

\begin{abstract}
Brazilian post-graduation: its asymmetric construction and some attempts to overcome. The following text deals with the origin and development of the postgraduate system in Brazil, from its implementation in the 1960s to the present day. For this, an analysis is made especially of the National Postgraduate Plans. In spite of a regular increase in the number of programs and scientific production, over the period analyzed, regional and spatial asymmetries and inequalities are also reproduced asymmetries and inequalities is also intensified. Such asymmetries generate interesting impacts to think about the future of scientific production in the country, especially those linked to the logic that favors graduate programs located in the south, southeast regions and the Federal District.
\end{abstract}

Keywords: postgraduate; asymmetries; science; inequality.

\section{Resumen}

El Postgrado brasileño: su construcción asimétrica y algunos intentos de superación. El texto siguiente trata del origen y desarrollo del sistema de postgrado en Brasil, desde su implementación en la década de 1960 hasta la actualidad. Para ello se realiza un análisis especialmente de los Planes Nacionales de Postgrado. Se percibe que, a pesar de un incremento regular en el número de programas y en la producción científica, durante el período analizado, son reproducidas las asimetrías y desigualdades regionales y espaciales. Tales asimetrías generan impactos interesantes para pensar en el futuro de la producción científica en el país, especialmente aquellos vinculados a la lógica que favorece los programas de posgrado ubicados en las regiones sur, sureste y el Distrito Federal.

Palabras clave: postgrado; asimetrías; la ciencia; desigualda. 
Em 1965, em razão de uma solicitação do Ministro da Educação e Cultura (MEC) Raymundo Moniz de Aragão (1912-2001), o Conselho Federal de Educação (CFE) iniciou o processo de regulamentação da Pós-Graduação no Brasil, já prevista no artigo 69 da Lei de Diretrizes e Bases da Educação Nacional de 1961. Atendendo à solicitação do MEC, o CFE emitiu o parecer n. 977/1965, de cuja comissão fizeram parte, além do relator Newton Sucupira (1920-2007), nomes bastante representativos da intelectualidade brasileira, entre eles Alceu Amoroso Lima (1883-1983) e Anísio Teixeira (1900-1971).

Grande parte da estrutura do que viria a ser a Pós-Graduação stricto sensu brasileira foi fundamentada neste Parecer 977, cujo objetivo primordial seria, então, corrigir deficiências estruturais existentes principalmente na formação docente e na qualificação de quadros voltados à produção científica e que contribuíssem com o desenvolvimento nacional.

A partir desse parecer, pode-se constatar que a pós-graduação stricto sensu no Brasil e sua regulamentação foram criadas sob a égide de duas constatações. Em primeiro lugar, houve o reconhecimento da dependência brasileira, inclusive no campo da educação superior, em relação aos países mais avançados economicamente, como é o caso dos Estados Unidos da América.

O Parecer 977, no tópico que trata das "Origens históricas da Pós-Graduação", reconhece a influência do modelo universitário estadunidense, seguindo-o pari passu, fundamentalmente na caracterização do Graduate School e dos cursos de pós-graduação, que se diferenciam essencialmente dos cursos de especialização, considerando-se a formação de mestres e doutores. O stricto sensu, de acordo com o documento, é de natureza acadêmica e voltado para a pesquisa, tendo objetivos científicos.

O nível de detalhamento do parecer e de semelhança com o modelo estadunidense foi tamanho que se chega a utilizar termos idênticos como, por exemplo, área de concentração e critérios de seletividade, ainda adotados atualmente: prova de língua estrangeira, prova escrita e defesa do projeto de pesquisa e, no caso das teses de doutorado, ineditismo do tema tratado.

Essa dependência reproduz, no âmbito acadêmico de produção e divulgação do conhecimento, o desenho centro periferia, no qual os países do capitalismo central produzem e os países periféricos consomem o que por eles é produzido (Santos, 2003). Essa mesma lógica foi reproduzida internamente em relação ao desenvolvimento e ao apoio à pós-graduação no
Brasil. Para Coronil (2005), em relação ao neoliberalismo, trata-se de um sistema que "conecta centros poderosos a periferias subordinadas. Seu modo de integração é fragmentário, ao invés, de total. Constrói semelhanças sobre uma base de assimetrias. Em suma, unifica dividindo" (p. 50).

Dessa forma, e em segundo lugar, constata-se claramente que a formação da pós-graduação no país é baseada na noção de assimetria, especialmente no que se refere ao investimento em alguns poucos centros de excelência, localizados em centros de poder político e econômico, desenvolvendo espaços elitistas e hierárquicos, assim como faz crescer as assimetrias regionais, tornando desiguais o acesso e a produção de conhecimento entre os distintos espaços de cada região. Tal situação de assimetria e hierarquia promove impactos no acesso e na produção de conhecimento científico no país, como se verá.

A maior parte da população brasileira foi excluída, desde o início, da possibilidade de acesso à pós-graduação, pensada a partir de um caráter elitista. Tal situação começa apenas a se transformar a partir das políticas de ação afirmativas, especialmente implementadas na década de 2000 , na graduação, e, posteriormente, na pós-graduação de algumas instituições. Nesse sentido, acaba-se por excluir grandes contingentes populacionais presentes no país, os quais poderiam apresentar outras epistemologias e regimes de conhecimento, complexificando e enriquecendo a ciência nacional. Para Apinajé e Herbetta (2018), deixa-se de lado a possibilidade de uma pluriversidade, em detrimento de um processo de "violência epistêmica presente na imposição e na reprodução de uma matriz de conhecimentos eurocentrada, o que acontece normalmente nas academias brasileiras" (p. 1).

Nessa mesma direção, para Dietz e Mateus (2011), acerca de processos de dominação em sociedades latino-americanas, afirma que:

O reconhecimento do caráter colonial das sociedades latino-americanas nos leva a intuir o caráter igualmente colonial de seus sistemas de conhecimento, de seu conhecimento. Essas continuidades e seu impacto em nossas percepções e autoimagens levantam a necessidade de uma "reconstituição epistemológica" (p. 59, tradução nossa).

Em janeiro de 1968 foi criado, por meio do Decreto-Lei n. 62.937, do então Presidente militar Arthur da Costa e Silva (1899-1969), o Grupo de Trabalho sobre a Reforma Universitária. O relatório apresentado pelo grupo em agosto de 1968 reconhecia 
a impossibilidade de contemplar todas as instituições de ensino superior em razão da escassez de recursos. Desse modo, por meio da Política Nacional de Centros Regionais de Pós-Graduação, o incentivo para a criação de cursos de pós-graduação seria destinado para aquelas instituições que "tivessem atingido um grau mínimo de desenvolvimento compatível com a natureza da pós-graduação" (Ministério da Educação e Cultura, 1983, p. 43).

De acordo com Schwartzman (2001), entretanto, houve, a partir dos anos 1970, uma tendência ao financiamento das pesquisas em ciência e tecnologia graças às "novas fontes de financiamento e pela flexibilidade institucional causada pelo surgimento de agências de planejamento econômico no campo de ciência e tecnologia" (p. 8). De acordo com esse autor, o montante de recursos destinados à ciência e tecnologia era tal que sobrava dinheiro. De toda forma, essas premissas resultaram na centralização da criação e dos recursos destinados à pós-graduação para as regiões Sudeste, Sul e o Distrito Federal, fundamentalmente para os estados do Rio de Janeiro e São Paulo, bem como para aquelas instituições de ensino superior que estivessem à altura das expectativas, tais como Universidade Federal do Rio de Janeiro (UFRJ) e Pontifícia Universidade Católica (PUC-Rio), Universidade de São Paulo (USP) e Universidade Estadual de Campinas (Unicamp), Universidade Federal de Minas Gerais (UFMG), Universidade Federal do Rio Grande do Sul (UFRGS) e Universidade de Brasília (UnB).

Aos gestores das agências de fomento interessava financiar esses centros, que eram, de acordo com seus critérios de avaliação, os mais promissores. Todo esse processo gerou discrepâncias e desigualdades entre as Universidades e seus institutos e departamentos, pois alguns contavam com expressivas somas de investimentos e outros mal conseguiam sobreviver.

Nessa direção, o objetivo fundamental deste artigo é demonstrar, por meio da análise dos seis Planos Nacionais de Pós-Graduação (PNPG), como ocorreu a construção da pós-graduação stricto sensu brasileira a partir dos anos 1960, cujo marco histórico foi o Parecer n. 977/1965, e como eles trataram a questão das assimetrias regionais no processo de expansão e consolidação do Sistema Nacional de Pós-Graduação.

\section{Método}

\section{Amostra e Procedimentos}

Por meio da análise dos seis Planos Nacionais de Pós-Graduação (PNPG) pretende-se entender como foram tratadas as questões relacionadas às assimetrias regionais e quais foram as propostas apresentadas para sua resolução. Os PNPGs surgiram a partir de 1975 e tinham como objetivo fundamental organizar o planejamento e a expansão do Sistema Nacional de Pós-Graduação (SNPG). Desde o primeiro plano, lançado em 1975, o Brasil conheceu outros cinco PNPG, tendo sido o último lançado em 2011.

A análise das assimetrias e desigualdades regionais em tela toma como base igualmente a análise detalhada de documentos fundantes do projeto de elaboração da pós-graduação stricto sensu no Brasil, como a Resolução n. 977/1965. Nesta análise, busca-se entender como alguns dispositivos mantêm e reproduzem caracteres de assimetria e hierarquia fortemente presentes no país. Ademais, compara-se a análise dos PNPGs e da documentação com a literatura do campo da decolonialidade.

\section{Resultados}

O I Plano Nacional de Pós-Graduação (PNPG) (1975-1979), contou, dentre suas diretrizes com a perspectiva de institucionalizar o sistema nacional de pós-graduação, garantindo estabilidade em termos de acesso aos recursos e o planejamento de sua expansão considerando o conjunto das regiões brasileiras. Coube à Capes, a partir de 1978, a tarefa de realizar as avaliações dos Programas de Pós-Graduação e a elaboração dos demais Planos Nacionais de Pós-Graduação a partir de 1981 (Hostins, 2006).

O I PNPG surgiu durante o governo de Ernesto Geisel (1907-1996) e esteve sob a responsabilidade do "Conselho Nacional de Pós-Graduação, instituído no Ministério da Educação e Cultura pelo Governo Federal, através do Decreto no. 73.411, de 4 de janeiro de 1974." (Capes, 1975, p. 119). A criação do Conselho e do PNPG teve origem a partir de uma solicitação do MEC que, em 1973, resolveu criar uma política de pós-graduação nacional.

O documento menciona a existência de 50 instituições de ensino superior nas quais se realizam cursos de pós-graduação: 25 federais, 10 estaduais e municipais e 15 particulares (Capes, 1975, p. 121). Em 1973, foram preenchidas 7.000 vagas, existindo um total de 13.500 alunos matriculados em diferentes fases. Em 1973, "O sistema titulou, até 1973 , cerca de 3.500 mestres e 500 doutores, dos quais cerca de $50 \%$ foram absorvidos pelo magistério e os demais pelo mercado de trabalho profissional." (Capes, 1975, p. 121) 
O I PNPG destaca o isolamento e a pouca articulação entre os programas existentes que sobrevivem, em grande parte, graças às iniciativas locais em termos de administração e financiamento. $O$ documento ressalta a forte demanda existente em termos de formação, ressaltando duas demandas específicas: $1^{\mathrm{a}}$ - formar, em volume e diversificação, pesquisadores, docentes e profissionais; $2^{\text {a }}$ - encaminhar e executar projetos de pesquisa, assessorando o sistema produtivo e o poder público.

A questão das assimetrias regionais é mencionada na seção destinada ao diagnóstico da situação à época, ressaltando que há uma concentração geográfica que, em função de uma migração "pós-universitária", ocorria no sentido do interior para as grandes capitais.

Naquilo que considera como diretrizes essenciais em relação às diferentes regiões do país, afirma que é necessário:

(...) planejar sua expansão em direção a uma estrutura mais equilibrada entre as áreas de trabalho educacional e científico e entre as regiões do País, minimizando a pressão atualmente suportada por esta parte do sistema universitário, aumentando a eficácia dos investimentos, e ampliando o patrimônio cultural e científico. (Capes, 1975, p. 126)

Quanto à alocação dos recursos, o documento é bastante genérico e não apresenta claramente quais serão as fontes das quais viriam e para onde iriam esses recursos: "Os recursos a serem alocados no sistema nacional de pós-graduação representam encargos adicionais para os vários órgãos financiadores, em relação aos seus orçamentos atuais." (Capes, 1975, p. 141). São citados o MEC e o CNPq como órgãos fornecedores de bolsas e auxílio para mestrandos, doutorandos e professores.

No item 3.3, Planejamento da Expansão, ficou definido que a pós-graduação seria um subsistema do sistema universitário que é, por sua vez, parte integrante do sistema educacional brasileiro, estando, portanto, subordinado ao restante do planejamento estatal. Não há menção explícita às diferentes regiões do país, a não ser quando o documento faz referência "a buscar uma polarização geoeducacional na implantação e ampliação de cursos de mestrado e doutorado, consciente das expansões geossociais previstas para o período no âmbito dos planos nacionais de desenvolvimento econômico e social." (Capes, 1975, p. 147).

No II PNPG (1982-1985), a questão das disparidades regionais foi tratada de forma mais clara, pois assinala que, para o atendimento dos objetivos propostos, deveriam ser considerados os desníveis entre regiões e instituições. Nesse caso, as medidas adotadas devem objetivar a superação dos efeitos negativos provocados pela heterogeneidade regional e institucional, visando atender as regiões mais pobres em relação à formação de recursos humanos que contribuam para minimizar os efeitos do atraso econômico.

Um dos aspectos mais destacados no II PNPG esteve relacionado à instabilidade quanto aos recursos destinados, sobretudo à pesquisa na Pós-Graduação. Em relação às agências de fomento, o documento adverte que "estão sujeitas a ocasionais reformulações de prioridades e reorientações políticas cujas consequências nem sempre se harmonizam com as necessidades de estabilidade e previsibilidade de que o sistema de pós-graduação carece para a sua consolidação e seu amadurecimento." (Capes, 1982, p. 180).

O documento enfatiza que a maioria das instituições privadas não tem tradição e nem condições fundamentais para o desenvolvimento da pesquisa ou para empregar profissionais em tempo integral (Capes, 1982, p. 183). A mesma situação pode ser encontrada em IES públicas de menor porte, nas quais os docentes destinam muito tempo à atividade de ensino em detrimento das atividades de pesquisa e produção científica.

O III PNPG (1986-1989) surge sob a égide do primeiro governo da Nova República, capitaneado pelo Presidente José Sarney. Esse foi um dos momentos mais importantes da história política brasileira. A transição democrática, iniciada no final dos anos 1970, com o movimento pela anistia, a volta do movimento sindical classista e independente, o fim do bipartidarismo da Aliança Nacional Renovadora (ARENA) e do Movimento Democrático Brasileiro (MDB) e a luta por eleições diretas culminam com a Constituinte de 1986 e a Constituição de 1988.

Mudanças de alcance significativo no campo da educação são previstas na nova Constituição, dentre elas o reconhecimento do Brasil como um país pluriétnico e plurilíngue, o que levaria, alguns anos depois, à adoção de políticas afirmativas, como a inclusão de indígenas e afrodescendentes no sistema universitário brasileiro (Nazareno \& Araújo, 2018). Por outro lado, se a conjuntura política é bastante rica em termos de mobilização e participação popular, por outro as agruras da crise econômica não dão trégua ao Brasil.

O III PNPG reiterou, mais uma vez, a necessidade de formação de recursos humanos capazes de assegurar a independência econômica, científica e tecnológica do Brasil. Nesse sentido, o Plano Nacional de

Estudos de Psicologia, 24(2), abril a junho de 2019, 103-112 
Pós-Graduação objetiva formar cientistas em quantidade e qualidade para atender o modelo de desenvolvimento brasileiro. Quanto à natureza desse modelo, pouco se sabia e pouco se explicava. Entretanto, o III PNPG reconhece os avanços dos dois Planos anteriores quanto à conformação e à institucionalização da Pós-Graduação, a formação de recursos humanos de alto nível e a melhoria da qualidade dos cursos de pós-graduação (Capes, 1986, p. 193).

No plano também há o reconhecimento da necessidade do desenvolvimento da pesquisa nas universidades e a aproximação destas ao mercado, além da integração da pós-graduação ao Sistema Nacional de Ciência e Tecnologia.

Para atingir os objetivos gerais previstos, foi "elaborado, como Anexo ao III PNPG, o Plano de Metas para Formação de Recursos Humanos e Desenvolvimento Científico (1987-1989)" (Capes, 1986, p. 195).

No ponto 2 do documento, Premissas do III PNPG, há um aspecto que prevê a expansão da base científica nacional, o que pode ser entendido como uma tentativa de diminuir as assimetrias regionais; contudo, a exemplo dos demais Planos, não há uma alusão clara aos mecanismos que seriam utilizados para tanto. É bem verdade que houve uma expansão dos programas de pós-graduação no país. Entre 1975 e 1985, de 370 programas de mestrado e 89 de doutorado, em 1975, houve um aumento bastante significativo, saltando para 787 cursos de mestrado e 325 de doutorado, em 1985.

Outro aspecto muito importante a destacar é que o sistema de avaliação e classificação dos cursos promovidos pela Capes, por meio de conceitos que correspondiam a notas que iam de A (nota máxima) a SA (sem avaliação), demonstrava que existia um nível razoável de qualificação dos programas no país. Os programas de mestrado e doutorado com nota $A$, o que seria o equivalente hoje à nota 7, passaram, no caso do doutorado, de 23, em 1977, para 36, em 1985, e no mestrado saiu de 22 para 33 no mesmo período (Capes, 1986, p. 198).

No entanto, o III PNPG alertava que $40 \%$ dos Programas apresentavam problemas como indefinições e baixa produtividade, saturação do número de orientandos por orientador, altos índices de evasão e elevado tempo médio de titulação.

Outro aspecto que merece destaque no documento trata da alusão feita pela primeira vez, em que pese a ausência de recursos financeiros, ao surgimento das Fundações de Apoio à Pesquisa. Quanto ao desenvolvimento científico regional, o documento ressalta a "ausência de uma política de apoio aos grupos emergentes e de desenvolvimento científico e regional" (Capes, 1986, p. 202). O III PNPG apresentou, pela primeira vez, dados sobre a distribuição geográfica da capacitação de pessoal em nível de pós-graduação stricto sensu, que, em 1982, estava assim distribuída: Região Norte, 0,85\%; Região Nordeste, 11,03\%; Região Centro-Oeste, 3,13\%; Região Sudeste, 74,21\%; e Região Sul, 10,75\% (Capes, 1986, p. 203).

Esses dados falam por si só acerca da concentração dos programas de pós-graduação no país e, consequentemente, da distribuição dos recursos destinados ao sistema de pós-graduação. De fato, essa realidade na chamada década perdida pouco se alteraria nos anos seguintes. Em um dos pontos relacionados à estratégia do III PNPG para o período, o documento assevera a necessidade de "apoiar a criação de novos programas de pós-graduação, somente quando a instituição tiver grupos de pesquisa com produção científica regular na área" (Capes, 1986, p. 210).

Os anos 1990 anunciavam ainda mais turbulências políticas e econômicas para o país. O IV PNPG, que deveria suceder o III PNPG, não seria sequer oficialmente reconhecido. Cria-se, assim, entre 1989 e a década de 1990, um hiato em relação à implementação do que deveria ser o novo plano. De qualquer forma, nos anos 1990 é instituída uma série de medidas na área da educação, tendo em vista a regulamentação do que estava previsto na Constituição de 1988. Para tanto, em 1996 é promulgada a Lei de Diretrizes e Bases da Educação Nacional (LDBEN), a Lei nº 9.394/1996.

Nesse momento, as políticas voltadas para o financiamento da pós-graduação brasileira estiveram fortemente ligadas à perspectiva da produtividade. Os recursos seriam repassados pelo governo, levando em conta a quantidade de estudantes e a produção docente e discente, bem como o desempenho institucional e o nível de internacionalização dos programas (Hostins, 2006; Ivashita \& Vieira, 2017).

Outras mudanças no sistema de pós-graduação estiveram relacionadas à diminuição do número de bolsas e à sua duração, à redução do período para realizar o mestrado e à vinculação das dissertações e teses aos projetos de pesquisa das instituições, sede dos programas, bem como o incentivo à formação de pós-graduação stricto sensu profissional.

O que deveria ter sido o IV PNPG, apesar das discussões iniciais em 1996, a partir do Seminário Nacional Discussão da Pós-Graduação Brasileira, 
não foi oficialmente reconhecido, a despeito dos documentos referentes a ele terem circulado internamente na Capes. O insucesso em relação à construção do IV PNPG foi atribuído, segundo Martins (2005 citado por Hostins, 2006), ao cenário de crise econômica do final dos anos 1990, que comprometeu o orçamento que garantiria a execução do IV PNPG e a falta de interlocução com as demais agências de fomento que historicamente participaram da elaboração dos planos.

De qualquer modo, sendo oficializado ou não, algumas medidas presentes no documento elaborado, mas não reconhecido oficialmente, foram executadas, dentre elas "a expansão do sistema nacional de pós-graduação, a diversificação do modelo vigente de pós-graduação de modo a atender também ao meio profissional, as mudanças no processo de avaliação, a implantação do portal de periódicos e inserção internacional da pós-graduação." (Martins, 2005 citado por Hostins, 2006, p. 146).

O V PNPG (2005-2010), elaborado durante o primeiro mandato do Presidente Lula, que teve início em 2003, reconheceu, desde o início do documento, as conquistas realizadas por meio do Sistema Nacional de Pós-Graduação ao longo de sua trajetória, enfatizando a necessidade de aprimorá-lo. Nesse sentido, o plano tem como um de seus objetivos fundamentais uma "expansão do sistema de pós-graduação que leve a expressivo aumento do número de pós-graduandos requeridos para a qualificação do sistema de ensino superior do país, do sistema de ciência e tecnologia e do setor empresarial" (Capes, 2004, p. 9).

Ocorreu, segundo o documento, uma ampla consulta a interlocutores qualificados da comunidade científica com vistas a elaborá-lo. Em junho de 2004 , são convidadas diversas entidades representativas da comunidade científica e da sociedade civil e, em julho de 2004, foram realizadas "audiências com os Fóruns Regionais de Pós-Graduação, cobrindo as cinco grandes regiões do país." (Capes, 2004, p. 9).

O documento reconhece o enorme avanço do Sistema Nacional de Pós-Graduação em números de alunos matriculados no mestrado e doutorado. Em 1987, havia 29.281 alunos matriculados no mestrado e 7.914 no doutorado. Em 2003, esse número saltou para 72.001 alunos no mestrado e para 40.2013 no doutorado (Capes, 2004, p. 31).

Mesmo com números tão expressivos em relação ao crescimento de alunos matriculados nos programas de pós-graduação, como se pode ver nas Tabelas 1 e 2, o
V PNPG reconhece que persiste a desigualdade regional em termos de distribuição do sistema, "uma vez que a região Sudeste concentra $54,9 \%$ dos cursos de mestrado e $66,6 \%$ dos de doutorado, seguida da região Sul (19,6\% e $17,1 \%)$, Nordeste (15,6\% e 10,3\%), Centro-Oeste $(6,4 \%$ e $4,1 \%$ ) e Norte (3,5\% e 1,8\%) (Capes, 2004, p. 31).

Tabela 1. Número de cursos segundo as regiões, 1996-2004

\begin{tabular}{lcccc}
\hline \multicolumn{3}{c}{ Região } & \multirow{2}{*}{ Mestrado } & \multicolumn{2}{c}{ Porcentagens } \\
\hline Sudeste & \multirow{2}{*}{ 2004 (21/05) } & & 1996 & 2004 (21/05) \\
\cline { 4 - 5 } Sul & 1685 & 1.076 & 63,3 & 54,9 \\
Nordeste & 155 & 384 & 15,3 & 19,6 \\
Centro-Oeste & 53 & 126 & 14,3 & 15,6 \\
Norte & 24 & 68 & 4,9 & 6,4 \\
Total & 1.083 & 1.959 & 100,0 & 3,5 \\
\hline Fonte: Capes (2004). & & & & 100,0 \\
\hline
\end{tabular}

Tabela 2. Número de cursos segundo as regiões, 1996-2004

\begin{tabular}{|c|c|c|c|c|}
\hline \multicolumn{5}{|c|}{ Doutorado } \\
\hline \multirow{2}{*}{ Região } & \multirow{2}{*}{1996} & \multirow{2}{*}{$2004(21 / 05)$} & \multicolumn{2}{|c|}{ Porcentagens } \\
\hline & & & 1996 & $2004(21 / 05)$ \\
\hline Sudeste & 450 & 689 & 83,2 & 66,6 \\
\hline Sul & 50 & 177 & 9,2 & 17,1 \\
\hline Nordeste & 22 & 107 & 4,1 & 10,3 \\
\hline Centro-Oeste & 12 & 42 & 2,2 & 4,1 \\
\hline Norte & 7 & 19 & 1,3 & 1,8 \\
\hline Total & 541 & 1.034 & 100,0 & 100,0 \\
\hline
\end{tabular}

As taxas de crescimento mostram um aumento maior na região Norte ( $15 \%$ ao ano), seguido das regiões Centro-Oeste (12\%), Sul (12\%), Nordeste $(9,6 \%)$ e Sudeste (6,3\%) (Capes, 2004, p. 32). O V PNPG reconheceu que o crescimento observado não foi capaz de diminuir as assimetrias entre as regiões e entre os estados.

Nesse cenário de manutenção das assimetrias entre as regiões, os desafios a serem enfrentados demandam "a) uma flexibilização do modelo de pós-graduação, a fim de permitir o crescimento do sistema; e b) uma atuação em rede, para diminuir os desequilíbrios regionais na oferta e desempenho da pós-graduação e atender às novas áreas de conhecimento" (Capes, 2004, p. 42).

Em relação ao item b, o V PNPG ressalta que, mesmo tendo sido objeto da preocupação dos Planos anteriores, com políticas orientadas para atenuar as 
diferenças entre as regiões, tais políticas não foram implementadas e "o sistema continua concentrado na região sudeste." (Capes, 2004, p. 45). O documento observa que, na região Centro-Oeste, as assimetrias são ainda mais acentuadas em razão da concentração da Pós-Graduação em Brasília, Distrito Federal.

Como proposta para proporcionar a distribuição mais equitativa dos recursos, o plano propõe "que, para as áreas geográficas, IV (Nordeste, menos Maranhão e Piauí, mais Espírito Santo) e V (Norte e Centro-Oeste, sem o Distrito Federal, acrescentando Maranhão e Piauí), as parcelas percentuais do acréscimo de orçamento previsto para a expansão do sistema acompanhem a distribuição de docentes." (Capes, 2004, p. 46), ou seja, que a distribuição dos investimentos adicionais seja diretamente proporcional ao número de docentes vinculados aos programas.

O VI PNPG (2011-2020) foi lançado em dezembro de 2010, último ano do segundo mandato do presidente Lula. Logo na introdução, a questão das assimetrias e sua possível resolução é colocada em destaque:

O combate às assimetrias é outro tema importante, cuja complexidade irá exigir a ação sinérgica de vários órgãos de governo envolvidos. A novidade será o foco nas mesorregiões, cuja formatação dará aos órgãos de governo uma ferramenta mais precisa que o foco em unidades e em macrorregiões (Capes, 2010, p. 18).

O capítulo sete do VI PNPG, "Assimetrias distribuição da pós-graduação no território nacional", reconhece o esforço realizado pelos planos anteriores em considerar o problema e tentar resolvê-lo a partir das iniciativas adotadas, sobretudo a partir do V PNPG, por meio de política de incentivo e indução. Como exemplo, tem-se "o procedimento dos fundos setoriais, que destina $30 \%$ dos seus recursos às políticas científicas e de pós-graduação para as regiões Norte, Nordeste e Centro-Oeste." (Capes, 2010, p. 145).

O documento apresenta duas perguntas iniciais como pontos para reflexão acerca das assimetrias:

1 - definir as políticas de indução e incentivo à pós-graduação com um olhar nas regiões e nas unidades da federação é eficaz na redução das assimetrias? 2 - A redução das assimetrias deve ter como alvo a produção de homogeneidade de indicadores de pós-graduação e entre áreas do conhecimento em todas as unidades da federação? (Capes, 2010, p. 146)

Em relação à primeira questão levantada, o VI PNPG trouxe uma inovação metodológica para análise das assimetrias regionais. Ao analisar a distribuição dos dados disponibilizados pela Capes não por unidades da federação, mas por mesorregiões geográficas, verificou-se que as regiões metropolitanas, principalmente as litorâneas, concentram a excelência da pós-graduação nacional. Essa nova metodologia permite observar que os objetivos do V PNPG de redução das assimetrias, por meio da indução e considerando a atração e a fixação de doutores em regiões com baixos índices de desenvolvimento da pós-graduação foram em parte atendidos, porém, o VI PNPG demonstrou que os entes federados possuem mesorregiões com relevantes assimetrias em relação aos mesmos indicadores.

Em parte, os objetivos do PNPG 2005-2010 na redução das assimetrias foram, pelo menos em parte, atingidos; entretanto, uma análise mais refinada permitiu verificar que todas as unidades da federação possuem mesorregiões com significativas assimetrias nos mesmos indicadores, sugerindo que as políticas de indução na redução dessas assimetrias devem contemplar a análise dos indicadores nacionais por mesorregiões brasileiras. Nesse caso, as políticas de indução deveriam contemplar a análise dos indicadores nacionais por mesorregiões (Capes, 2010, p. 146).

O diagnóstico realizado por meio das mesorregiões permitiria um nível mais preciso em relação aos diferentes graus de consolidação na formação de recursos humanos no sistema de pós-graduação, que vão desde a incipiência até a excelência, seja qual for a unidade da federação ou macrorregião analisada. Esse diagnóstico permitiria orientar as políticas estratégicas de desenvolvimento científico e tecnológico e tornaria possível identificar a vocação de cada mesorregião e o posterior processo de interiorização do ensino superior (Capes, 2010, p. 146).

\section{Discussão}

O grande desafio apresentado pelo I PNPG esteve relacionado à formação de professores qualificados como mestres e doutores. Nesse sentido, a meta era formar 16.800 mestres e 1.400 doutores, ampliando as 7.000 vagas antes oferecidas para cerca de 11.700 vagas anuais de mestrado, e de 500 para cerca de 1.200 vagas anuais de doutorado ao final do quinquênio 1975-1979.

Vale ressaltar que, no quadro 2-B do I PNPG (Capes, 2010, p. 157), que trata da capacidade nominal de atendimento em cursos de mestrado e doutorado para início de 1975, a distribuição percentual por região 
apresentava as regiões Sudeste e Sul com capacidades percentuais de $79 \%$ para mestrado e $98 \%$ para doutorado. Esses dados demonstram, por si só, que grande parte dos recursos destinados ao Plano foram para essas duas regiões.

O II PNPG, apesar de afirmar que um de seus objetivos é "incentivar o sistema a melhor se dimensionar tendo em vista as especificidades de cada área de conhecimento, os tipos de qualificação requeridos e as necessidades regionais" (Capes, 2010, p. 186), não apresenta claramente quais seriam os meios para atender tais necessidades. Quando muito, salienta que pela expansão de novos cursos os objetivos podem ser cumpridos.

Como enfatizado anteriormente, a questão das disparidades regionais é levantada de forma um pouco mais clara, entretanto, em termos de planejamento e execução, muito pouco é apresentado.

No final dos anos 1980, a conjuntura econômica e política se torna mais grave. Fernando Collor de Mello é eleito presidente do país, mas sofre impeachment em 1992. Assumiu em seu lugar seu vice, Itamar Franco (1930-2011). Esse foi um período de implantação, em toda a América Latina, das medidas econômicas relacionadas ao que ficou conhecido como "Consenso de Washington", que previa, entre outras medidas, a liberalização econômica, com a privatização das empresas públicas, aumento das taxas de juros como fator de atração dos investimentos externos diretos, desregulamentação do mercado laboral, dentre outros. (Nazareno, 2003).

Assim, o Plano, que foi efetivado na prática sem nunca ter sido oficialmente reconhecido, realizou algumas modificações bastante significativas no sistema de pós-graduação. O sistema de avaliação, com base nos conceitos que variavam entre $\mathrm{A}$ e $\mathrm{E}$, dava claros sinais de esgotamento, pois não era capaz, nas palavras de Martins (2003, p. 305), de discriminar a qualidade entre os programas. "Na avaliação de 1996, 79\% dos cursos de mestrado e $90 \%$ dos de doutorado obtiveram conceito 'A' ou 'B'."

A década de 1990, segundo Ivashita e Vieira (2017), foi um marco na criação de programas de pós-graduação em diferentes regiões do país. De acordo com Martins (2000, p. 52-54), "No final da década de 60 , a pós-graduação tinha aproximadamente 100 cursos, abrangendo não mais de dois mil alunos. Atualmente conta com 2.066 cursos cobrindo todas as áreas do conhecimento, vários deles com excelente padrão acadêmico". Em 1990, havia, no Brasil, 964 cursos de mestrado e 450 cursos de doutorado; em 1998, esses números subiram para 1.339 e 727 , respectivamente.
O V PNPG aponta para a necessidade de estratégias que visem a evolução do sistema tendo em vista as necessidades nacionais, tentando interromper a continuidade das assimetrias regionais nos próximos anos. Uma das estratégias adotadas foi a descentralização dos recursos por meio da criação/do fortalecimento das Fundações de Apoio à Pesquisa nos estados.

Em relação ao diagnóstico apresentado no documento, foram destacadas quatro vertentes:

(...) a capacitação do corpo docente para as instituições de Ensino Superior, a qualificação dos professores da educação básica, a especialização de profissionais para o mercado de trabaIho público e privado e a formação de técnicos e pesquisadores para empresas públicas e privadas (Capes, 2004, p. 48).

No item 3.8 do V PNPG, "Potencialidades e debilidades da pós-graduação", ressaltam-se como principais debilidades, entre outros pontos, as assimetrias entre as regiões e estados e entre as áreas de conhecimento, bem como a falta de articulação entre as agências de fomento e as Fundações de Amparo à Pesquisa dos estados.

Como estratégia para mitigar as assimetrias regionais, foi proposta como linha programática, visando reduzir as diferenças regionais, a indução de programas: "A indução estratégica de programas de Pós-Graduação ou programas prioritários de pesquisa deverá ser operacionalizada através do aporte de recursos adicionais." (Capes, 2004, p. 53).

O VI PNPG reiterou a necessidade de manutenção e ampliação dos grupos de excelência, programas com notas 6 e 7, mas que deveriam atuar como promotores da consolidação dos grupos emergentes, como é o caso dos programas com notas 3 e 4 .

A proposta de indução para a diminuição das assimetrias regionais, apresentadas no $\mathrm{V}$ e $\mathrm{VI}$ PNPG, alterou substancialmente a realidade regional no Sistema Nacional de Pós-Graduação. Os dados demonstram que o número de cursos de mestrado passou, somente na região Centro-Oeste, de 113, em 2004, para 177, em 2009, um crescimento de $56,6 \%$. Em relação aos cursos de doutorado para o mesmo período, houve um crescimento de $63 \%$, pois, em 2004 , existiam 47 cursos de doutorado, passando a contar com 77 cursos em 2009. Apesar disso, mantem-se as assimetrias, sobretudo aquelas ligadas à lógica que privilegia alguns programas de pós-graduação, com avaliação superior a 5 , localizados nas regiões sul, sudeste e o Distrito Federal. 


\section{Conclusões}

A partir da criação e do desenvolvimento da pós-graduação stricto sensu, o Brasil passou a figurar no cenário internacional em termos de produção acadêmica. Prova disso é que, de 812 artigos publicados em 1973, passou para 1.551 em 1980, com produção concentrando-se em universidades da região Sudeste, como USP, Unicamp e Universidade Estadual Júlio de Mesquita - Unesp (Schwartzman, 2001). Tal incremento se vê igualmente no número de programas. Em 1970, havia, no Brasil, 57 programas de doutorado, número que saltou, em 1985, para mais de 300 cursos de doutorado e cerca de 800 de mestrado (Schwartzman, 2001).

Contudo, o crescimento do sistema de pós-graduação se deu a despeito do desenvolvimento de assimetrias presentes no acesso de distintas populações e produção de conhecimento científico. Para Coronil (2005), o estabelecimento de assimetrias regionais e espaciais é parte do processo de dominação presente no mundo contemporâneo (p. 50-62).

Pode-se perceber, portanto, que a marca da assimetria, da hierarquia e da desigualdade ainda é um dos grandes desafios do sistema de pós-graduação no país. Essas assimetrias podem ser observadas tanto em relação às regiões político-administrativas brasileiras, quando se observa que as regiões Sudeste e Sul, desde o início, recebem mais incentivos, quanto dentro de uma mesma região, quando se nota que os maiores centros urbanos, ao longo do tempo, concentram os esforços de promoção da pós-graduação no país.

$\mathrm{O}$ aparente milagre acadêmico em termos de expansão, indesejada a princípio e aparentemente incontrolável depois, não gerou os resultados esperados. Essa situação causa problemas estruturais para o desenvolvimento da pesquisa no país, pois dificulta o acesso e a permanência de grandes contingentes populacionais na pós-graduação, por conta dos problemas decorrentes de deslocamento e renda. Dessa forma, as populações mais pobres não acedem ao nível da pós-graduação, mantendo-se esses espaços como elitistas.

Ademais, considerando que a questão da renda no país tem relação direta com os temas de raça e etnia, pode-se concluir que o espaço elitista e desigual da pós-graduação tem ainda enorme dificuldade em receber e se apropriar da diversidade presente no país. Nessa direção, a ciência brasileira deixa de se articular com uma série de distintas epistemologias, que certamente poderia tornar a produção nacional ainda mais potente.
Para Wallerstein (2004), o sistema mundial moderno enfrenta uma bifurcação fundamental. Passa por uma crise sistêmica, que consequentemente também afeta as estruturas do conhecimento. Assim, temos diante de nós não uma, mas duas grandes incertezas sociais: qual será a natureza do novo sistema histórico que estamos construindo e qual será a epistemologia de nossas novas estruturas e conhecimentos (p. 48).

Um Sistema Nacional de Pós-Graduação que procure ter em toda a sua extensão um caráter mais simétrico deve ter a capacidade de, entre outras coisas, contemplar outras epistemologias presentes em nossas diferentes regiões dando conta do desafio histórico apontado acima por Wallerstein.

\section{Referências}

Apinajé, J. K. R., \& Herbetta, A. (2018). Cantos filosóficos e a possibilidade de uma pluridiversidade. Articulando e Construindo Saberes, 3(1), 55-62. doi: 10.5216/racs.v3i1.55373

Coordenação de Aperfeiçoamento de Pessoal de Nível Superior Capes. (1975). I PlanoNacionalde Pós-Graduação-PNPG. Recuperado de https://www.capes.gov.br/plano-nacional-de-pos-graduacao

Coordenação de Aperfeiçoamento de Pessoal de Nível Superior Capes.(1982). IIPlano Nacional de Pós-Graduação-PNPG. Recuperado de https://www.capes.gov.br/plano-nacional-de-pos-graduacao

Coordenação de Aperfeiçoamento de Pessoal de Nível Superior Capes. (1986). IIIPlanoNacional de Pós-Graduação-PNPG. Recuperado de https://www.capes.gov.br/plano-nacional-de-pos-graduacao

Coordenação de Aperfeiçoamento de Pessoal de Nível Superior Capes.(2004). IVPlanoNacional dePós-Graduação-PNPG. Recuperado de https://www.capes.gov.br/plano-nacional-de-pos-graduacao

Coordenação de Aperfeiçoamento de Pessoal de Nível Superior Capes. (2010). Plano nacional de pós-graduação [PNPG] 2011-2020, Vol. I. Brasília, DF: CAPES. Recuperado de https://www.capes.gov.br/ images/stories/download/Livros-PNPG-Volume-I-Mont.pdf

Conselho Federal de Educação (1965). Parecer nํ 977/65. Recuperado de https://www.capes.gov.br/images/stories/download/avaliacao/ avaliacao-n/Parecer-977-1965.pdf

Coronil, F. (2005). Natureza do pós-colonialismo: do eurocentrismo ao globocentrismo. In E. Lander (Org.), A colonialidade do saber: eurocentrismo e ciências sociais Perspectivas latino-americanas (pp. 55-68). Buenos Aires, Argentina: Colección Sur Sur - CLACSO.

Dietz, G., \& Mateos Cortés, L. S. (2011). Interculturalidad y educación intercultural en México. Un análisis de los discursos nacionales e internacionales en su impacto en los modelos educativos mexicanos. México: Secretaria de Educación Publica (SEP).

Hostins, R. C. L. (2006). Os Planos Nacionais de Pós-graduação (PNPG) e suas repercussões na Pós-graduação brasileira. Perspectiva, 24(1), 133-160. doi: 10.5007/\%25x

Ivashita, S. B., \& Vieira, A. D. R. (2017). A pós-graduação no Brasil e o Plano Nacional de Pós-graduação - PNPG (2011-2020): rupturas e permanências. Debates em Educação, 9(19). 121-132. doi: 10.28998/2175-6600.2017v9n19p121

Martins, C. B. (2000). O ensino superior brasileiro nos anos 90 . Perspectiva, 14(1), 41-60. doi: 10.1590/S0102-88392000000100006 
A pós-graduação brasileira: sua construção assimétrica e algumas tentativas de superação

Martins, C. B. (2003). Balanço: o papel da CAPES na formação do sistema nacional de pós-graduação. In M. M. Ferreira \& R. L. Moreira (Orgs.), CAPES 50 anos: depoimentos ao CPDOC/FGV (pp. 294-309). Rio de Janeiro: Fundação Getulio Vargas/CPDOC; Brasília, DF: Capes.

Ministério da Educação e Cultura (1983). Secretaria da Educação Superior. Reforma Universitária - Relatório do Grupo de Trabalho criado pelo Decreto n. 62.937/68. Recuperado de http://www.dominiopublico.gov.br/ download/texto/me002285.pdf

Nazareno, E. (2003). Integración Económica Europea, Mercosur y Alca: consecuencias para el mundo del trabajo (Tese de Doutorado, Universidade de Barcelona, Espanha). doi:10.13140/RG.2.2.31922.45767
Nazareno, E., \& Araújo, O. C. G. (2018). História e diversidade cultural indígena na Base Nacional Comum Curricular (2015-2017). Temporis[Ação], 18(1), 35-60. Recuperado de https://www.revista. ueg.br/index.php/temporisacao/article/view/6658

Santos, C. M. (2003). Tradições e contradições da pós-graduação no Brasil. Educação \& Sociedade, 24(83), 627-641. doi: 10.1590/ S0101-73302003000200016

Schwartzman, S. (2001). Um espaço para a ciência: a formação da comunidade científica no Brasil. Brasília, DF: Ministério de Ciência e Tecnologia/Centro de Estudos Estratégicos.

Wallersteins, I. (2004). Las incertidumbres del saber. Barcelona: Gedisa.

Elias Nazareno, Doutor em Sociologia pela Universidade de Barcelona, Espanha, Pós-doutor pela Universidade de Coimbra, Portugal, é Professor Associado da Universidade Federal de Goiás - UFG. Endereço para correspondência: Núcleo Takinahaky de Formação Superior Indígena - Universidade Federal de Goiás -

Av. Esperança, s/n - Chácaras de Recreio Samambaia, Goiânia - GO. CEP 74.690-900. Email: eliasna50@gmail.com

Alexandre Ferraz Herbetta, Doutor em Antropologia Social pela Pontifícia Universidade Católica de São Paulo - PUC/SP, é Professor Adjunto da Universidade Federal de Goiás - UFG. Email: alexandre_herbetta@yahoo.com.br

Recebido em 13.jun.19 Revisado em 17.set.19 Aceito em 31.dez.19 